\title{
Analisis Kualitatif Kandungan Fenolik dalam Fraksi Etil Asetat dan Fraksi Metanol dari Ekstrak Kulit Jagung (Zea mays L.)
}

\author{
Yuniarthi Dwi Suputria ${ }^{a 1^{*}}$, Agus Dwi Ananto ${ }^{a, 2}$, Yayuk Andayani a,3 \\ aprogram Studi Farmasi, Fakultas Kedokteran, Universitas Mataram, J1. Majapahit No.62, Dasan Agung Baru, Mataram, 83I26 \\ 1yuniarthidwi@gmail.com*; ${ }^{2}$ agus_da@unram.ac.id; ${ }^{3}$ yayukmtr@gmail.com \\ *korespondensi penulis
}

INFO ARTIKEL
Diterima :
28-I2-2020
Disetujui :
04-0I-202I

\section{Kata kunci:}

Kulit jagung;

Kromatografi lapis tipis;

Analisis kualitatif.

\section{ABSTRAK}

Produksi tanaman jagung yang semakin meningkat menyebabkan peningkatan limbah kulit jagung semakin tinggi. Kulit jagung dapat dimanfaatkan dalam bidang kesehatan dan berpotensi sebagai antioksidan. Kulit jagung mengandung senyawa fenolik dan flavonoid yang dapat bertindak sebagai antioksidan. Tujuan dari penelitian ini adalah untuk mengetahui kandungan senyawa pada fenolikfraksi etil asetat dan fraksi metanol kulit jagung. Ekstraksi kulit jagung dilakukan dengan metode maserasi menggunakan pelarut etanol 96\%. Fraksinasi ekstrak etanol kulit jagung dilakukan dengan fraksinasi bertingkat menggunakan pelarut metanol dan etil asetat. Kedua fraksi yang diperoleh kemudian dianalisis secara kualitatif dengan metode Kromatografi Lapis Tipis. Fase diam yang digunakan adalah plat silica gel $\mathrm{G}_{60} \mathrm{~F}_{254}$ dan fase gerak yang digunakan adalah kombinasi eluen kloroform: etil asetat: n-butanol: asam format (5:2:2:I). Hasil pemisahan ditandai dengan munculnya noda bercak saat diamati dengan sinar UV $254 \mathrm{~nm}$ dan $366 \mathrm{~nm}$. Nilai Rf bercak yang muncul kemudian dihitung lalu dibandingkan dengan nilai $\mathrm{Rf}$ literatur untuk mengidentifikasikan senyawa yang terpisah. Hasil analisis kualitatif fraksi etil asetat dan fraksi metanol kulit jagung menunjukkan keberadaan senyawa fenolik. Hasil ini ditunjukkan dengan munculnya noda bercak dengan nilai $\mathrm{Rf} 0,75$ yang memiliki kemiripan dengan nilai $R f$ asam galat $(0,76)$.

Key word:

Cornhusk;

Thin layer chromatography;

Qualitative analysis.

\section{ABSTRACT}

Corn production keeps increasing causing increasing in corn husk waste. Cornhusk can be used in medical field and have potential as an antioxidant. Cornhusk contains phenol and flavonoid metabolites that can act as antioxidants. The aim of this study is to determine the presence of phenol metabolites in ethyl acetate and methanol fraction of cornhusk. Cornhusk extraction was carried out by a maceration method using ethanol 96\%. Fractionation of ethanolic cornhusk extract was carried out by liquid-liquid extraction using a separating funnel with methanol and ethyl acetate solvent. The two fractions then analyzed qualitative by Thin Layer Chromatography. The stationary phase used is silica gel $\mathrm{G}_{60} \mathrm{~F}_{254}$. The mobile phase used is a combination of chloroform: ethyl acetate: n-butanol: formic acid (5:2:2:I). The separation result marked by the presence of stains when observed by UV 254 $\mathrm{nm}$ and $366 \mathrm{~nm}$ light. The Rf value then measured and compared to Rf value in the literature to determine the separated substance. The qualitative analysis result of corn husk ethyl acetate fraction and methanol fraction indicated the presence of phenolic metabolites. This result is showed by the presence of stain with $R f$ value 0,75 that has similarity with $R f$ value of gallic acid $(0,76)$.

This is an open access article under the CC-BY-SA license. 


\section{Pendahuluan}

Potensi flora Indonesia sebagai obat sangat besar. Berbagai jenis flora di Indonesia terkenal dengan manfaatnya yang berlimpah. Masyarakat Indonesia cenderung kembali ke alam untuk memanfaatkan berbagai flora sebagai bahan obat (Wasito, 20II). Selain lebih ekonomis, penggunaan tanaman sebagai alternatif pengobatan dirasa lebih aman dan efektif (Putri dan Rahayu, 2013).

Salah satu tanaman yang dapat dimanfaatkan khasiatnya adalah jagung (Zea mays L.). Keberadaan jagung di Indonesia terbilang cukup banyak, salah satunya di Lombok Timur. Data Badan Pusat Statistik pada tahun 2015 menunjukkan bahwa produksi jagung di Nusa Tenggara Barat mencapai 959.973 ton. Budidaya jagung terbilang cukup mudah dan memiliki prospek ekonomi baik sehingga dapat menjamin ketersediaan bahan baku alami. Sebagian besar masyarakat menggunakan jagung sebagai bahan makanan dimana kulit dan tongkolnya seringkali dibuang begitu saja (Nawaz, dkk., 2018).

Pada tahun 2015 tercatat produksi jagung di Indonesia sebesar 19.6I2.435 ton dengan limbah kulit jagung mencapai 38,38\% (BPS, 2015). Tingginya limbah kulit jagung ini sangat disayangkan padahal kulit jagung memiliki manfaat dalam bidang kesehatan. Hal ini dikarenakan kandungan metabolit sekundernya. Menurut Brobbey dkk. (2017) senyawa metabolit sekunder yang terdapat dalam ekstrak metanol kulit jagung adalah tanin, saponin, alkaloid, flavonoid, fenol dan glikosida. Pada ekstrak air diperoleh senyawa metabolit sekunder berupa saponin, alkaloid, flavonoid dan glikosida. Fidrianny (2016) juga melaporkan mengenai kandungan flavonoid dan fenolik dari kulitjagung. Oleh karena itu, kulit jagung dapat berpotensi sebagai obat, salah satunya sebagai antioksidan.

Pemilihan metode ekstraksi harus diperhatikan agar diperoleh hasil ekstraksi yang maksimal. Secara umum, metabolit sekunder seperti fenolik dan flavonoid merupakan senyawa metabolit sekunder yang tidak tahan terhadap temperatur tinggi serta dapat teroksidasi oleh suhu yang tinggi (Koirewoa dkk., 2012). Oleh karena itu, penggunaan metode maserasi cocok digunakan untuk mendapatkan metabolit sekunder seperti fenolik, flavonoid dan saponin secara lebih baik. Selain metode ekstraksi, perlu diperhatikan pula pelarut ekstraksi yang digunakan. Pada penelitian ini digunakan pelarut etanol. Etanol merupakan pelarut polar yang cocok digunakan untuk menarik senyawa-senyawa polar seperti fenolik, flavonoid dan saponin (Koirewoa dkk., 20I2).

Berdasarkan hal tersebut, untuk mempertimbangkan kemungkinan pengaplikasian kulit jagung (Zea mays L.) sebagai antioksidan yang terjamin kualitas dan keamanannya, maka diperlukan kajian awal mengenai keberadaan metabolit sekundernya. Dalam hal ini, metabolit sekunder yang diteliti adalah senyawa fenolik. Penelitian ini akan mengetahui kandungan senyawa fenolik dalam fraksi etil asetat dan fraksi metanol kulit jagung. Dengan demikian, hasil penelitian ini diharapkan dapat memberikan dasar penunjang potensi kulit jagung sebagai antioksidan.

\section{Metode}

\section{Alat dan Bahan}

Bahan-bahan yang digunakan pada penelitian ini adalah sampel kulit jagung diperoleh dari Pasar Tradisional Pagesangan, Mataram,pelarut etanol $96 \%$ (teknis), pelarut metanol (p.a), serbuk $\mathrm{FeCl}_{3}$, $\mathrm{HCl}$, n-butanol, larutan asam format, kloroform, dan etil asetat diperoleh dari Merck. Alat-alat yang digunakan adalah Spektrofotometer UV-Visible (Double beam spectrophotometer), plat silica gel 60 GF254 (Merck), lampu UV.

\section{Persiapan Sampel Penelitian}

Sebanyak 3,5 kg sampel kulit jagung diambil dari Pasar Tradisional Pagesangan, Mataram. Sampel disortasi basah, dicuci, dirajang, dan dikeringkan dengan cara dijemur di bawah sinar matahari dengan dilapisi kain hitam. Hasil simplisia kulit jagung kering disortasi kering kemudian dihaluskan dengan blender hingga diperoleh serbuk simplisia kulit jagung.

\section{Ekstraksi dan Fraksinasi}

Metode ekstraksi mengikuti metode yang dilakukan oleh Samin, dkk (20I4) dengan beberapa modifikasi pada bagian perbandingan simplisia dan pelarut serta pada proses pemekatan ekstrak kulit jagung. Simplisia sebanyak 350 gram dimaserasi menggunakan etanol 96\% selama 4 × 24 jam, dimana penyaringan ekstrak dilakukan setiap 24 jam. Kemudian, dimaserasi dengan pelarut etanol $96 \%$ baru. Proses maserasi dibantu pengadukan sesekali agar proses ekstraksi berjalan maksimal. Seluruh filtrat yang diperoleh digabungkan kemudian diuapkan dengan penangas air sederhana pada suhu $\leq 50^{\circ} \mathrm{C}$ sehingga diperoleh ekstrak kental etanol kulit jagung.

Fraksinasi ekstrak dilakukan dengan menggunakan metode yang dilakukan oleh Sudarma (20I4) dengan beberapa modifikasi. Fraksinasi dilakukan dengan mensuspensikan ekstrak kental menggunakan pelarut metanol:air (I:I). Partisi kemudian dilakukan dengan menggunakan etil asetat. Perbandingan antara metanol dan etil asetat yang 
digunakan adalah I:I. Terakhir, mengentalkan hasil fraksinasi dengan penangas air sederhana pada suhu $\leq 50^{\circ} \mathrm{C}$ sehingga diperoleh ekstrak kental tiap fraksi.

\section{Skrining Fitokimia}

Uji Fenolik

Fraksi sebanyak $0, \mathrm{I}$ gram dilarutkan dengan I0 $\mathrm{mL}$ akuades kemudian disaring sehingga diperoleh filtratnya. Selanjutnya, filtrat direaksikan dengan 3 tetes $\mathrm{FeCl} 3 \mathrm{I} \%$. Munculnya warna hijau biru kehitaman menandakan hasil yang positif (Alfian dan Susanti, 2012).

\section{Analisis Kualitatif dengan Kromatografi Lapis Tipis (KLT)}

Analisis kualitatif dilakukan menggunakan metode Kromatografi Lapis Tipis (KLT). Fase diam yang digunakan adalah silica gel G60F254 (Merck). Fase gerak untuk analisis fenolik adalah kloroform: etil asetat: n-butanol: asam format (5:2:2:I) (Kemenkes, 2017).

\section{Hasil dan Pembahasan}

\section{Persiapan Sampel}

Sebanyak 3,5 kg sampel kulit jagung yang diperoleh dari Pasar Tradisional Pagesangan, Mataram dibuat menjadi simplisia sebelum dilakukan proses ekstraksi. Simplisia kulit jagung dibuat dengan melakukan sortasi basah, pencucian, perajangan, pengeringan, sortasi kering, pengemasan, dan penyimpanan (Prasetyo dan Inoriah, 2013). Sebanyak 1200 gram simplisia kering kemudian dihaluskan dengan cara dry blender.

\section{Ekstraksi dan Fraksinasi}

Metode maserasi merupakan metode ekstraksi cara dingin yang dapat menarik senyawa-senyawa termolabil (Fauzi, dkk., 2017). Proses maserasi simplisia kulit jagung dilakukan dengan merendam simplisia dalam pelarut etanol $96 \%$ menggunakan perbandingan simplisia dan pelarut I:IO. Pelarut etanol 96\% digunakan karena pelarut tersebut memiliki gugus polar dan non polar sehingga memiliki kemampuan untuk menarik senyawa polar, semi polar, ataupun non polar. Etanol juga merupakan pelarut yang tidak beracun sehingga aman digunakan dan mudah diperoleh (Fauzi, dkk., 2017). Pemilihan etanol juga didasarkan pada sifat senyawa yang akan ditarik. Pelarut polar akan menarik senyawa polar, sedangkan pelarut non polar akan menarik senyawa non polar (Mariana, dkk., 2013). Ekstrak kental etanol kulit jagung yang diperoleh setelah pemekatan adalah 22,I7I gram dengan persen rendemen ekstrak sebesar 6,33\%.
Fraksinasi ekstrak etanol kulit jagung dilakukan menggunakan metode ekstraksi cair-cair. Prinsip dari metode ini adalah menarik senyawa pada suatu ekstrak menggunakan dua pelarut yang tidak bercampur (Mutiasari, 20I2). Pelarut yang digunakan untuk proses fraksinasi adalah etil asetat dan metanol. Etil asetat merupakan pelarut semi polar sehingga dapat menarik senyawa kurang polar (Rollando, 2019). Metanol merupakan pelarut polar sehingga dapat menarik senyawa polar (Kusumaningtyas, dkk., 2008). Jumlah fraksi beserta persentase rendemen fraksi dapat dilihat pada tabel I.

Tabel I. Rendemen Fraksinasi

\begin{tabular}{cccc}
\hline Sampel & $\begin{array}{c}\text { Bobot } \\
\text { ekstrak } \\
(\mathrm{g})\end{array}$ & $\begin{array}{c}\text { Hasil } \\
(\mathrm{g})\end{array}$ & $\begin{array}{c}\text { Rendemen } \\
(\%)\end{array}$ \\
\cline { 1 - 3 } $\begin{array}{c}\text { Fraksi etil } \\
\text { asetat }\end{array}$ & $\mathrm{I}$ & 7,449 & $5 \mathrm{I}, 75$ \\
\cline { 1 - 1 } $\begin{array}{c}\text { Fraksi } \\
\text { metanol }\end{array}$ & & 2,109 & $\mathrm{I} 4,65$ \\
\hline
\end{tabular}

\section{Skrining Fitokimia}

Golongan senyawa yang terdapat dalam fraksi etil asetat dan fraksi metanol dapat dilihat melalui proses skrining fitokimia (Simaremare, 20I4). Hasil skrining fitokimia pada fraksi etil asetat dan fraksi metanol positif mengandung senyawa fenolik. Hal ini ditandai dengan adanya perubahan warna larutan sampel menjadi hijau kehitaman.Hasil skrining fitokimia senyawa fenolik dapat dilihat pada gambar 2. Perubahan warna yang terjadi disebabkan oleh senyawa fenol mereduksi $\mathrm{Fe}^{3+}$ menjadi $\mathrm{Fe}^{2+}$ yang berwarna biru kehitaman (besi (III) hesasianoferat) (Hanani, 2015). Mekanisme reaksi uji fenolik dapat dilihat pada gambar I.

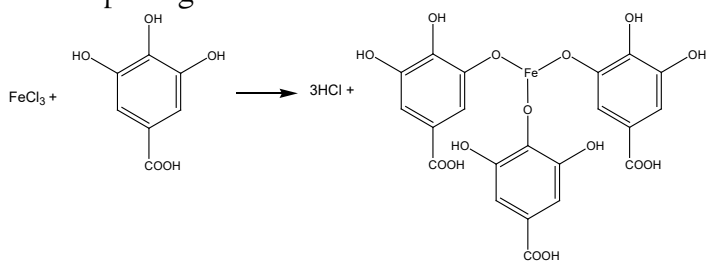

Gambar I. Mekanisme uji fenolik

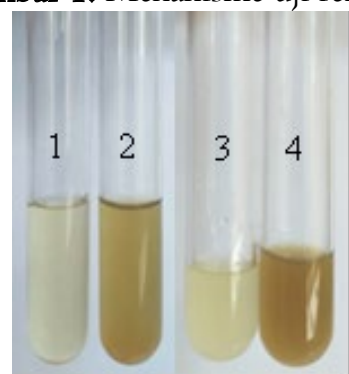

Gambar 2.Hasil skrining fitokimia senyawa fenolik 
Keterangan:

$\mathrm{I}=$ hasil skrining fraksi etil asetat sebelum ditambahkankan $\mathrm{FeCl3}$

$2=$ hasil skrining fraksi etil asetat sesudah ditambahkankan $\mathrm{FeCl3}$

$3=$ hasil skrining fraksi metanol sebelum ditambahkankan $\mathrm{FeCl3}$

$4=$ hasil skrining fraksi metanol sesudah ditambahkankan $\mathrm{FeCl} 3$

\section{Analisis Kualitatif dengan Kromatografi Lapis Tipis (KLT)}

Analisis kualitatif fraksi etil asetat dan fraksi metanol kulit jagung dilakukan dengan menggunakan Kromatografi Lapis Tipis (KLT). Analisis kualitatif ini digunakan untuk menegaskan keberadaan kandungan metabolit sekunder yang terdapat dalam fraksi etil asetat dan fraksi metanol kulit jagung (Fath, 2016). Prinsip pemisahan metode KLT adalah pemisahan campuran berdasarkan perbedaan interaksi sampel dengan fase gerak dan fase diamnya (Rubiyanto, 2017).

Pengujian KLT dilakukan menggunakan beberapa kombinasi eluen untuk pemisahan senyawa fenolik, flavonoid, dan saponin. Kombinasi eluen yang digunakan untuk pemisahan fenolik adalah kloroform: etil asetat: n-butanol: asam format (5:2:2:I). Kombinasi eluen ini memiliki kepolaran yang cenderung non polar. Hal ini dapat dilihat melalui perbandingan kloroform yang lebih banyak. Kloroform merupakan eluen non polar ditandai dengan konstanta dielektriknya, yaitu 4,8I (Stahl, 1985). Eluen ini dapat memberikan pemisahan yang cukup baik pada fraksi etil asetat dan fraksi metanol kulit jagung. Pemisahan yang baik ditandai dengan komponen senyawa yang dihasilkan cukup banyak, noda terlihat bagus, dan pemisahan nodanya terlihat jelas (Markham, 1988).

Fase diam yang digunakan adalah plat silica gel $\mathrm{G}_{60} \mathrm{~F}_{254}$. Plat silica gel ini kemudian digunakan untuk menotolkan sampel fraksi etil asetat dan fraksi metanol kulit jagung yang telah di peroleh. Sampel ditotolkan dengan jarak I cm dari bagian bawah plat. Totolan dibuat sekecil mungkin agar pemisahan yang terjadi lebih optimal (Gandjar, 2007). Hasil pemisahan berupa bercak noda dihitung untuk memperoleh nilai $\mathrm{Rf}$ dan diidentifikasikan senyawa menggunakan hasil warna KLT beserta nilai Rf. Nilai Rf adalah rasio antara jarak yang ditempuh oleh sampel dengan jarak yang ditempuh oleh pelarut (Sherma dan Fried, 2003).

Berdasarkan tabel 2, dapat diketahui bahwa fraksi etil asetat dan fraksi metanol kulit jagung mengandung senyawa fenolik. Hasil ini ditandai dengan adanya bercak dengan nilai $\mathrm{Rf}$ 0,75 pada pemisahan fenolik yang serupa dengan nilai $R f$ asam galat $(0,76)$ sehingga dapat diasumsikan bahwa terdapat senyawa fenolik asam galat (Kemenkes, 2017).

Tabel 2. Hasil Analisis Kualitatif Fraksi

\begin{tabular}{ccc}
\hline \multirow{2}{*}{ Sampel } & \multicolumn{2}{c}{ Rf Pemisahan Fenolik } \\
\cline { 2 - 3 } & UV 254 & UV 366 \\
& nm & nm \\
\hline \multirow{2}{*}{ Fraksi Etil } & 0,125 & 0,125 \\
Asetat & 0,75 & 0,75 \\
& 0,8125 & 0,8125 \\
\hline Fraksi Metanol & 0,125 & 0,125 \\
\hline
\end{tabular}

\section{Simpulan dan Saran}

Hasil analisis kualitatif dari fraksi etil asetat dan fraksi metanol kulit jagung menunjukkan adanya golongan senyawa fenolik. Hasil ini ditunjukkan dengan munculnya noda bercak dengan nilai Rf 0,75 yang memiliki kemiripan dengan nilai $\mathrm{Rf}$ asam galat $(0,76)$.

\section{Daftar Pustaka}

Agustiningsih, Wildan, A., dan Mindaningsih. (2010). Optimasi cairan penyari pada pembuatan ekstrak daun pandan wangi (Pandanus amaryllifous Roxb) secara maserasi terhadap kadar fenolik dan flavonoid total. Momentum; 6(2), 36-4I.

Alfian, R. Dan Susanti, H. (2012). Penetapan kadar fenolik total ekstrak metanol kelopak bunga rosella merah (Hibiscus sabdariffa Linn) dengan variasi tempat tumbuh secara spektrofotometri. Pharmaciana; 2(I), 7380.

Badan Pusat Statistik. Produksi Jagung Menurut Provinsi (ton) 1993-2015, diakses dari https://bps.go.id/linkTableDinamis/view $\angle \mathrm{id} / 868$

Brobbey, A.A., (2017). Preliminary phytochemical screening and scientific validation of the anti-diabetic effect of the dried husk of Zea mays L. (Corn, Poaceae). International Journal of Phytopharmacy. 7(I), 0I-5.

Dewi, N.L.A., Adnyani, L.P.S., Pratama, R.B.R., Yanti, N.N.D., Manibuy, J.I., dan Warditiani, N.K. (2018). Pemisahan, isolasi, dan identifikasi senyawa saponin dari herba pegagan (Centella asiatica L. Urban). Jurnal Farmasi Udayan; 7(2), 6876.

Fath, M.A. (2016).Profil kromatografi lapis tipis ekstrak etanol biji adas (Foeniculum vulgare Mill), rimpang kencur (Kaempferia galangal L.), rimpang kunyit putih (Curcuma zedoria (Berg.)Roscoe), herba pegagan (Cantella 
asiatica) serta ramuannya.Skripsi. Malang: Universitas Islam Negeri Maulana Malik Ibrahim Malang.

Fauzi, N.P., Sulistiyaningsih, dan Runadi, D. (2017). Uji aktivitas antibakteri ekstrak etanol dan fraksi daun jewer kotok (Coleus atropurpureus (L.) Benth.) terhadap bakteri Propionibacterium acnes ATTC 1223 dan Staphylococcus epidermidis ATTC 12228. Farmaka; 15(3), 45-55.

Fidrianny, I., Wulandari, E., dan Hartati, R., (2016). In vitro antioxidant activity of different organs extracts of corn grown in cimahiwest java-indonesia. International Journal of Pharmacognosy and Phytochemical Research. 8(6), I025-1032.

Gandjar, I.G. dan Rohman, A., (2007). Kimia Farmasi Analisis. Yogyakarta: Pustaka Pelajar.

Hanani, M.S.E. (2015). Analisis Fitokimia. Jakarta: Penerbit Buku Kedokteran EGC.

Harborne, J.B. (1987). Metode Fitokimia: Penuntun Cara Modern Menganalisis Tumbuhan. Bandung: Institut Teknologi Bandung.

Kemenkes. (2017). Farmakope Herbal Indonesia Edisi II. Jakarta: Kementerian Kesehatan Republik Indonesia.

Kusumaningtyas E., Widiati R. dan Gholib D. (2008). Uji daya hambat ekstrak dan krim ekstrak daun sirih (Piper betle) terhadap C. albicans dan Trichophyton mentagrophytes. Seminar Nasional Teknologi Peternakan dan Veteriner. Yogyakarta II-I0 Maret 2008.

Koirewoa, Y.A., Fatimawali., dan Wiyono, W.I., (20I2). Isolasi dan identifikasi senyawa flavonoid dalam daun beluntas (Pluchea indica L.). Pharmacon. I(I), 47-52.

Mariana, L., Andayani, Y., dan Gunawan, E.R. 2013. Analisis senyawa flavonoid hasil fraksinasi ekstrak diklorometana daun keluwih (Artocarpus camansi).Chemistry Progress, 6(2),50-55

Markham, K.R., (I988). Cara Mengidentifikasi Flavonoid. Diterjemahkan oleh KosasihPadmawinata. Bandung: Penerbit ITB.

Mutiasari, I.R., (20I2). Uji aktitas antioksidan ekstrak jamur dengan metode DPPH dan identifikasi golongan senyawa kimia dari fraksi teraktif. Skripsi. Fakultas Matematika dan Ilmu Pengetahuan Alam. Depok.

Nawaz, H., Muzaffar, S., Aslam, M., dan Ahmad, S., (2018). Phytochemical Composition:
Antioxidant Potential and Biological Activities of Corn. London: IntechOpen.

Wasito, H. (20II). Obat Tradisional Kekayaan IndonesiaEdisi Pertama. Yogyakarta: Graha Ilmu.

Prasetyo dan Inoriah, E. (2013) Pengelolaan Budidaya Tanaman Obat - Obatan (Bahan Simplisia). Bengkulu: Badan Penerbitan Fakultas Pertanian UNIB.

Putri, D.A. dan Rayahu, T., (2013). Aktivitas antibakteri ekstrak bawang putih (Allium sativum) dan black garlic terhadap eschericia coli sensitif dan multiresisten antibiotik. Jurnal Biologi UNS. 4, 390394.

Rollando. (2019). Senyawa Antibakteri Dari Fungi Endofit. Malang: CV. Seribu Bintang.

Rubiyanto, D., (2017). Metode Kromatografi: Prinsip Dasar, Praktikum, dan Pendekatan Pembelajaran Kromatografi. Yogyakarta: Deepublish.

Samin, A.A., Bialangi, N., dan Salimi, Y.K., (20I4). Penentuan kandungan fenolik total dan aktivitas antioksidan dari rambut jagung (Zea mays L.) yang tumbuh di daerah gorontalo. Jurnal SAINTEKS; 7(3), 2I3226.

Sherma, J. dan Fried, B., (2003). Handbook of ThinLayer Chromatography. New York: Marcel Dekker, Inc.

Simaremare, E.S. (20I4). Skrining fitokimia ekstrak etanol daun gatal (Laportea decumana (Roxb.) Wedd). Pharmacy; II(OI), 98I07.

Stahl, E. (I985). Analisis Obat Secara Kromatografi dan Mikroskopi. Bandung: ITB.

Sudarma, I.M., (20I4). Kimia Bahan Alam (Ekstraksi, Isolasi, dan Transformasi). Mataram: FMIPA Press. 